\title{
UM OLHAR SOBRE AS CONTRIBUIÇÕES DE LEV VIGOTSKI À EDUCAÇÃO DE SURDOS
}

\section{A LOOK AT THE CONTRIBUTIONS OF LEV VYGOTSKY TO EDUCATION OF THE DEAF}

\begin{abstract}
UMA MIRADA ACERCA LAS CONTRIBUCIONES DE LEV VIGOTSKI A LA EDUCACIÓN DE SORDOS
\end{abstract}

\author{
Daniele Siqueira Veras ${ }^{*}$ \\ Ana Cristina Silva Daxenberger*
}

\begin{abstract}
Resumo: A Educação de Surdos foi amplamente discutida na história da educação com argumentos apresentados por cada estudioso de áreas diferentes, baseados por filosofias e princípios educacionais que indicaram a melhor proposta para educação de surdos para cada época. Atualmente, as discussões estão voltadas com novos olhares para este fenômeno, que, apesar de todos os debates já realizados, ainda há o que se compreender e, efetivamente aplicar na educação de surdos. Vigotski é um dos maiores teóricos da Psicologia, denominada de sócio-histórica, e com grandes contribuições sobre a Psicologia da Aprendizagem e do Desenvolvimento, além da Educação. Aliado a isto, surge o questionamento: quais as contribuições de Lev Vigotski para a Educação de Surdos dentro de seus pressupostos básicos e dos Fundamentos de Defectologia. Em sua obra, Vigotski abre espaço para discussão das pessoas com deficiência e claro, para a educação de surdos. Portanto, são objetivos deste trabalho apresentar os principais conceitos da teoria de Vigotski; expor os fundamentos da Defectologia e relacionar a obra de Vigotski com a educação de surdos. Para alcançar estes objetivos, foi realizada uma pesquisa bibliográfica de textos do autor e releituras, além do arsenal teórico sobre a Educação de Surdos. Como resultados deste estudo, apontamos para as contribuições de Vigotski para a Educação de Pessoas com deficiência ao trazer conceitos de compensação social, deficiência primária e secundária e os caminhos alternativos do desenvolvimento. Especificamente sobre a Educação de Surdos, Vigotski aponta o lugar da linguagem neste desenvolvimento e faz uma crítica aos métodos oralistas.
\end{abstract}

Palavras-chave: Educação de surdos. Teoria vigotskiana. Inclusão escolar.

Abstract: The Education of the Deaf was widely discussed in the history of education with arguments presented by each student from different areas, based on philosophies and educational principles that indicated the best proposal for education of the deaf for each season. Nowadays, the discussions are focused with new looks for this phenomenon, which, despite all the debates already held, there is still something to be understood and effectively applied in the education of the deaf. Vigotski is one of the greatest theoreticians of psychology, which is called socio-historical, having a great contribution

\footnotetext{
* Doutoranda em Psicologia Cognitiva (UFPE). Professora da Faculdade São Miguel, Recife/PE, no curso de Licenciatura em Letras e coordenadora do curso de Fonoaudiologia. Professora da Faculdade Maurício de Nassau no curso de Pedagogia, em Caruaru/PE. E-mail: daniele.veras@gmail.com

** Doutora em Educação Escolar pela Universidade Estadual Júlio de Mesquita Filho. Chefe do DCFS/CCA da Universidade Federal da Paraíba. Professora da Universidade Federal da Paraíba e da UAB/UFPB, curso Letras Libras. E-mail: ana.daxenberger@gmail.com
} 
on the Psychology of Learning and Development, besides the Education. Allied to this, the question arises: What Lev Vigotski's contributions to the Education of the Deaf within his basic assumptions and of the Foundations of Defectology? In his work, Vigotski opens space for discussion of people with disabilities and of course, for the education of the deaf. Therefore, the objective of this work is to present the main concepts of Vigotski's theory; to expose the fundaments of Defectology and to relate the work of Vigotski to the education of the deaf. In order to reach these goals, a bibliographical research of author's texts and re-readings was carried out, besides the theoretical arsenal on the Education of the Deaf. The research's results are that the contributions of Vigotski to the Education of disabilities People by bringing concepts of social compensation, primary and secondary deficiency and the alternative paths of development. Specifically, on the Education of the Deaf, his contributions are the importance of the language and criticizes oral methods.

Keywords: Deaf education. Vigotskian theory. School inclusion.

Resumen: La Educación de Sordos fue discutida en la historia de la educación con argumentos presentados por cada estudioso de áreas diferentes, basados por filosofías y principios educativos sobre que indicaron la mejor propuesta para la educación de sordos. En la actualidad, las discusiones se centran en nuevas miradas para este fenómeno, buscando métodos alternativos en la educación de sordos. Vigotski es uno de los mayores teóricos de la Psicología, denominada de socio-histórica, y con grandes contribuciones sobre la Psicología del Aprendizaje y del Desarrollo, y de la Educación. Aliado a esto, surge el cuestionamiento: cuáles las contribuciones de Lev Vigotski para la Educación de Sordos dentro de sus presupuestos básicos y de los Fundamentos de Defecología. Vigotski discute sobre las personas con discapacidad y claro, para la educación de sordos. Por lo tanto, son objetivos de este trabajo presentar los principales conceptos de la teoría de Vigotski; exponer los fundamentos de la Defecología y relacionar la obra de Vigotski con la educación de sordos. Para alcanzar estos objetivos, se realizó una investigación bibliográfica de textos del autor y relecturas, además del arsenal teórico sobre la Educación de Sordos. Como resultados de este estudio, las contribuciones de Vigotski para la Educación de Personas con discapacidad al traer conceptos de compensación social, discapacidad primaria y secundaria y los caminos alternativos del desarrollo. En particular, sobre la educación de sordos, él discute sobre el lenguaje y una crítica a los métodos orales.

Palabras claves: Educación de sordos. Teoría vigotskiana. Inclusión escolar.

\section{Introdução}

A Educação de Surdos sempre abriu espaço para discussão de como a aprendizagem e o desenvolvimento das pessoas surdas deveria ser de fato (re)pensado. Para discutir sobre este desenvolvimento discutiremos a Educação de Surdos fundamentada na perspectiva de Lev Vigotski como alicerce teórico. Esta escolha deve-se ao fato desse autor destacar em sua obra os fundamentos da Defectologia (VIGOTSKI, 1997) abordando a educação e os processos psicológicos de pessoas com deficiência, entre eles, a surdez. Além da sua importante contribuição em nível de estudos e princípios do desenvolvimento, da aprendizagem e sua visão de sujeito sócio-histórico pautado no materialismo dialético. Sendo assim, quais as contribuições da teoria vigotskiana para a Educação de Surdos? É importante ressaltar que, para Vigotski, as formas culturais de comportamento são o único caminho para a educação da pessoa com deficiência.

A fim de responder esta pergunta, o objetivo geral desta pesquisa é identificar e discutir sobre as contribuições da teoria de Vigotski para a Educação de surdos e objetivos específicos, apresentar os principais 
conceitos da teoria de Vigotski; expor os fundamentos da Defectologia e relacionar a obra de Vigotski com a educação de surdos.

Para atingir este objetivo, foi realizada uma pesquisa de cunho bibliográfico nas obras de autoria de Vigotski, especificamente: a Construção do Pensamento e da Linguagem (VIGOTSKI, 2009), A Formação Social da Mente (VIGOTSKI, 2007), Psicologia Pedagógica (VIGOTSKI, 2010) e Obras Escogidas, Tomo V - Fundamentos de la Defectologia (VIGOTSKI, 2012) além dos pressupostos básicos e históricos da Educação de Surdos.

Em sua teoria de desenvolvimento das pessoas com deficiência, Vigotski (2010) traz o conceito de compensação, esta que não é biológica propriamente dita, mas sim social: é o superar as limitações com base em instrumentos, estratégias e meios para compensar a deficiência, o que seria realizado, por exemplo, o uso de imagens e legenda na Educação de Surdos. Vigotski (2011) apresenta a ideia de que é através da criação de caminhos indiretos de desenvolvimento, quando este resulta impossível por caminhos diretos, que será necessário a intervenção junto às crianças com deficiência.

Ainda sobre o processo de aprendizagem, Vigotski (2007) traz o conceito de Zona de Desenvolvimento Proximal (ZDP), a qual compreendemos como aquela que se situa entre o nível desenvolvimento real, a qual deve ser entendida como o ponto em que o sujeito é capaz de fazer e aprender por si só e a zona de desenvolvimento potencial, a qual é aquela em que o sujeito será capaz de alcançar e apreender com o auxílio do outro; sendo a mediação essencial para a construção do conhecimento.

Vigotski (2012) aponta que as pessoas que nascem surdas não sofrem diretamente a experiência da perda, mas, habitando um mundo cujos códigos sociais e demais parâmetros utilizados na vida diária são na maioria das vezes auditivos, não tardam a ter a experiência da deficiência. A plenitude de sua vida e a amplitude de seu território existencial depende bastante dos cuidados e da estimulação que recebem, bem como das oportunidades que lhes são oferecidas. Sendo assim, na perspectiva vigotiskiana a estimulação precoce é essencial para o desenvolvimento do sujeito, uma vez que quanto mais cedo for estimulado à aprendizagem pode ocorrer com mais plenitude e facilidade.

Na visão sócio-histórica de Vigotski, a criança surda adquire conceitos, assim como ouvintes, mas essa função cultural é garantida por um aparato psicofisiológico completamente diferente, a partir de caminhos alternativos. Para ele, a educação surge em auxílio na criação de técnicas artificiais, culturais, um sistema especial de signos ou símbolos culturais adaptados às peculiaridades da organização psicofisiológica da criança com deficiência.

Partindo da importância da contribuição de Vigotski para a educação, especificamente no que diz respeito à aprendizagem, entende-se que os pressupostos também serão de grande contribuição para a educação de pessoas com deficiência, por isso, a relevância em entender a visão vigotskiana da educação de surdos. Para entender esta relação se fez necessário primeiramente apresentar a teoria basilar de Vigotski e em seguida os aspectos voltados a Defectologia, logo após um panorama geral da Educação de Surdos e posteriormente a relação entre essas duas temáticas. Este trabalho trata-se de uma pesquisa bibliográfica, com abordagem crítica sobre as contribuições de Vigotski à educação de surdos. 


\section{Lev Semionovich Vigotski ${ }^{1}$ : a construção do ser social}

Os pressupostos filosóficos da teoria vigotskiana assim como da Psicologia SócioHistórica têm como base o materialismodialético. Alves (2010, p. 1) explica esta teoria:

Os princípios fundamentais do materialismo dialético são quatro: (1) a história da filosofia, que aparece como uma sucessão de doutrinas filosóficas contraditórias dissimula um processo em que se enfrentam o princípio idealista e o princípio materialista; (2) o ser determina a consciência e não inversamente; (3) toda a matéria é essencialmente dialética, e o contrário da dialética é a metafísica, que entende a matéria como estática e anistórica; (4) a dialética é o estudo da contradição na essência mesma das coisas.

Portanto, esta filosofia entende que o meio, o organismo e os fenômenos físicos presentes podem moldar o homem, assim como a sociedade e a cultura ou vice-versa. Vale salientar, que o contexto não será apenas um mero fator, deverá haver uma interação dialética entre o homem e o mundo, deve-se levar em conta as relações entre o sujeito, o uso de artefatos - assim como a interação mediada por instrumentos entre o homem e o mundo - e recursos simbólicos. Portanto, os sentidos serão produzidos dentro de um contexto histórico, com a visão de homem como um sujeito único, complexo e integral. Este sujeito tem suas características, mudanças históricas, psíquicas e materiais e estão associadas à sociedade em que vive.

Os postulados de Vigotski se expandiram pelo mundo e se tornaram base para

\footnotetext{
${ }^{1}$ Devido a não padronização, o nome do autor tem sido escrito de várias formas, como: Vygotsky, Vigotsky ou ainda Vigotskii. Adotaremos aqui a grafia Vigotski que é a que mais se aproxima do original russo.
}

novas formas de enxergar a aprendizagem e o desenvolvimento da criança, bem como o entendimento das funções psicológicas superiores, contribuindo com seus estudos para a Psicologia, e, principalmente, a Pedagogia.

\section{Os conceitos da teoria Vigotskiana}

Vigotski rompe com as teorias psicológicas mais evidentes na época, se afastando assim do subjetivismo; assim como das teorias comportamentais. Para ele, o desenvolvimento das funções psicológicas superiores é um fenômeno sócio-histórico, já que é estruturado nas atividades sociais do sujeito. Portanto, a cultura tem um papel relevante na vida do sujeito, pois é através dela que significados serão compartilhados, ou seja, diferentes culturas trarão sentidos e significados distintos ao sujeito.

Além das teorias fortemente ligadas a Psicologia da Aprendizagem e do Desenvolvimento, por exemplo, ao afirmar que a aprendizagem é fruto da interação entre o sujeito e o meio, Vigotski afirmar que o papel da escola na transmissão de conhecimento é de natureza diferente daqueles aprendidos na vida cotidiana. Vigotski (2004; 2007) instaurou um novo olhar sobre o método em Psicologia com a criação de novos olhares que se adequa nas novas maneiras de se colocar os processos psicológicos, ou seja, passa a perceber os processos e não o objeto final, assim como também apresenta a essência dos fenômenos ao invés de suas características perceptíveis.

Vigotski assegura que "o verdadeiro curso do desenvolvimento do pensamento não vai do individual para o socializado, mas do social para o individual” (VIGOTSKI, 2010, p. 17), portanto, para ele as origens das funções psicológicas superiores devem ser encontradas nas relações sociais que o sujeito constitui em contato com o mundo 
exterior, então, para ele a inserção na cultura favorecerá o desenvolvimento - que se dará "de fora para dentro”, ou seja, primeiramente cultural depois internalizado pelo sujeito, portanto, é a partir da interação que há o desenvolvimento cognitivo.

Este autor pondera que os primeiros anos de vida é um momento excepcional para analisar o desenvolvimento das funções psicológicas superiores, pois quando elas começam a se estabelecer, em um momento também de intenso desenvolvimento biológico, é apenas o pontapé inicial de uma história de modificações que durará a vida inteira. Portanto, Vigotski tenta compreender a gênese, a origem dos processos psicológicos. (VIGOTSKI, 2007).

Para Vigotski (2007), as funções psicológicas superiores são produtos da atividade cerebral, tem base biológica, mas fundamentalmente são resultados da interação do indivíduo com o mundo de forma mediada. São funções psicológicas superiores: imaginação, consciência, cognição, memória, linguagem e pensamento, sendo estas duas últimas, objetos de verticalização aqui neste estudo uma vez que trataremos sobre o desenvolvimento do pensamento de pessoas surdas e a aquisição de sua linguagem. É preciso esclarecer que as funções psicológicas superiores são aquelas mediadas por sistemas simbólicos e se diferem das funções inferiores, pois estas últimas são consideradas meros reflexos, ou seja, as funções psicológicas superiores do homem se diferem das dos outros animais, pois são de origens sociais e não intencionais. Estas funções se dão primeiramente na relação entre pessoa e depois passa a ser internalizada e constitui o sujeito.

Sendo assim, podemos afirmar que os principais elementos da teoria de Vigotski em relação ao desenvolvimento e aprendizagem são: a ideia de desenvolvimento prospectivo, a aprendizagem se estabelece antes do desenvolvimento e o outro como mediador cultural (o professor como principal mediador do desenvolvimento).

Uma das obras mais conhecidas de Vigotski, “A Construção do Pensamento e da Linguagem” (2010) teve sua primeira tradução - do inglês para o português - denominada como “Pensamento e Linguagem”, já a atual foi traduzida do russo e por isso a alteração do nome da obra. É neste trabalho que Vigotski faz grandes contribuições para a as teorias de aprendizagem e desenvolvimento.

Para Vigotski (2010) o signo é constitutivo do psiquismo e mediador das atividades mentais (instrumento das atividades mentais) produzidos nas relações interpessoais. Para ele, a relação entre mente, pensamento, linguagem e mundo é o sentido que o sujeito dá às suas experiências. A relação pensamento-linguagem tem como resultado o significado da palavra (que será a forma de acesso ao pensamento), podendo ser entendido como a soma de todos os fatos psicológicos que ela desperta na consciência do sujeito, além do compartilhamento de signos. É importante ressaltar que esses dois processos superiores não se separam e a relação entre eles é dinâmica e estão presentes na fase inicial do desenvolvimento da criança.

$\mathrm{O}$ autor enfatiza que, em determinado momento, por volta dos dois anos de idade,

As curvas do pensamento e da fala, até então separadas, cruzam-se e coincidem para iniciar um nova forma de comportamento característico do homem, a fala se torna intelectual e o pensamento verbalizado [...] é como se a criança descobrisse a função simbólica da linguagem. (VIGOTSKI, 2010, p. 130).

Podemos assumir que para Vigotski (2007; 2010) a linguagem estrutura o 
pensamento - este que surge, por exemplo, quando uma criança conta em voz alta - a chamada fala interior ou egocêntrica, não dirigida ao outro - sobre uma ação, ou seja, faz com que linguagem e o pensamento se encontram. Ainda assim, a linguagem ajuda a efetivar e controlar o comportamento.

Vigotski (2010) afirma que pensamento (pré-verbal) e linguagem (não-racional) caminham juntos. Exemplifica, por exemplo, que a interação da criança com o adulto permite a essa interiorizar a atividade prática expressa na atividade sensório-motora, através das vocalizações, fala interior e, finalmente, o pensamento (todo um processo de internalização).

Outro conceito importante para entender a teoria, foi abordado no texto A Formação Social da Mente (2007), quando Vigotski define Zona de Desenvolvimento Proximal ZDP. Para ele a ZDP é

Distância entre o nível de desenvolvimento real, que se costuma determinar através da solução independente de problemas, e o nível de desenvolvimento potencial, determinado através da solução de problemas sob a orientação de um adulto ou em colaboração com companheiros mais capazes. (VIGOTSKI, 2007, p. 97).

Portanto, podemos conceituar como a distância entre o desenvolvimento real e o potencial, com isso, a criança conseguiria solucionar problemas sob orientação de adultos e que em breve será capaz de realizar sozinha. Sendo assim, é na relação que se a criança se inicia a constituir como sujeito: quando estiverem construindo as zonas de desenvolvimento proximais.

Assim, a aprendizagem se dá na interação, troca com o outro, a partir disso há desenvolvimento. O desenvolvimento real trata-se do conhecimento que o aprendiz já possui, enquanto que o potencial é aquele ainda em construção, que ele ainda não consegue executar, sem a ajuda do outro. A aprendizagem, portanto, poderá ser efetiva com a criação de zonas de desenvolvimento proximais, pois, é justamente a partir da interação com os adultos (sujeitos mais experientes) que a criança será capaz de realizar com ajuda deste, logicamente a partir de seu próprio nível de conhecimento, ou desenvolvimento real, tarefas que não conseguiria realizar sozinha, autonomamente, assim, o adulto será, neste caso, o sujeito que favorecerá o desenvolvimento. Um detalhe importante sobre a ZDP é que Vigotski enfatiza: trata-se de um processo espiralado, não constante, ao contrário do que muitos imaginam como um processo cíclico.

Portanto, a aprendizagem e o desenvolvimento estão emaranhados desde o início da vida da criança que, através da imitação, da fala do outro, interrogando e buscando informações, adquire uma gama de informações variadas e este processo se dará ao longo de toda vida do sujeito.

Além disso, outro objeto de estudo de Vigotski é a mediação e o papel do outro no desenvolvimento. Para ele,

Desde os primeiros dias de desenvolvimento da criança, suas atividades adquirem um significado próprio num sistema de comportamento social e, sendo dirigida a objetos definidos, são refratadas através do prisma do ambiente da criança. O caminho do objeto até a criança e desta até o objeto passa através de outra pessoa. Essa estrutura humana complexa é o produto de um processo de desenvolvimento profundamente enraizado nas ligações entre história individual e história social. (VIGOTSKI, 2016, p. 40).

A mediação é uma constituição de cunho teórico que provoca o desenvolvimento dos sujeitos por meio de instrumentos e signos. Esses instrumentos produzidos pelo homem 
em sua participação junto à natureza e com os outros homens sofreram transformações, em importantes instrumentos de mediação no desenvolvimento dos processos psicológicos superiores. Para Vigotski, o homem inventa e usa instrumentos, que serão mediadores, no contato com o outro, e, consequentemente essas mediações e internalizações modificam os sujeitos e o mundo ao seu redor. Sendo assim, é viável ressaltar que Vigotski discute aprendizagem compreendendo-a como mudança (ZDP).

Como as relações entre os sujeitos constituem fundamentalmente a construção dos processos psicológicos, é nas interações com o outro sujeito que possui mais experiências que o homem organiza conceitualmente o mundo. O papel do outro mediador é basilar na teoria vigotskiana, pois ele é fundamental para a construção de conhecimento humano. Graças ao outro, o sujeito é apresentado às situações que não precisa viver por si mesmo, que lhe podem ser transmitidas pelo outro através da cultura.

Ao trazer o conceito de mediação, Vigotski traz o termo artefatos culturais como mediadores e amplificadores culturais (atuantes no desenvolvimento cognitivo e aprendizagem). Essa mediação será fundamental no processo de construção de significados, que serão internalizados pelo sujeito ao longo do seu processo de desenvolvimento. Portanto, os instrumentos que podem ser artefatos e mediadores culturais, podem ser exemplificados da seguinte forma: certas tarefas não-exequíveis pelo homem com seu equipamento biológico natural podem ser executadas com auxílio de instrumentos.

\section{Fundamentos de Defectologia}

O registro dos Fundamentos de Defectologia $^{2}$ faz parte do Tomo 5 das Obras

${ }^{2}$ Usaremos o termo Defectologia como Vigotski utilizou em sua obra. É importante ressaltar que os estudos
Escogidas de Lev Vigotski (2012), ainda não traduzidas para a Língua Portuguesa. Em seus estudos, Vigotski também contemplou a tentativa de compreender o desenvolvimento das pessoas com deficiência, incluindo pessoas surdas, cegas, com deficiência física ou intelectual.

Para ele, não é apenas mensurar a deficiência é ir, além disso: entendendo como o sujeito se organiza, afastando-se da pedagogia medicamentosa-hospitalar, quando o caminho ideal passa a ser o favorecimento das relações entre as funções psicológicas superiores, para beneficiar o desenvolvimento, salientando que a deficiência reorganizará todas essas funções, além de, mesmo no início do século passado, já ir contra as escolas chamadas especiais, pois a escola precisa vencer a deficiência.

Ao introduzir a temática Vigotski deixa claro que não irá seguir uma defectologia "antiga” que apenas pensava no desenvolvimento em termos quantitativos com base numa perspectiva positivista, realizando uma crítica a estes aspectos e se afastando deste olhar, se preocupando com a qualidade do desenvolvimento. Então, as formas culturais de comportamento serão os únicos caminhos para a educação da criança com deficiência. (VIGOTSKI, 2011).

O olhar tradicional, que tanto Vigotski critica, compreendia o defeito negativamente, portanto, significava: menos, falha, deficiência, limite. Estas significações consequentemente levavam o desenvolvimento da criança a ser caracterizado, como uma perda de alguma função biologicamente. Todos os estudos psicológicos das deficiências foram fundamentados, de forma geral, pela comparação das funções perdidas pela

e registros por ele realizados foram feitos, aproximadamente, entre 1920 e 1930 e, portanto, é natural que algumas nomenclaturas utilizadas por ele em sua obra não sejam mais utilizadas atualmente, como o termo surdo-mudo e anormal. 
criança com deficiência em relação àquelas sem deficiência.

A proposição do autor é de que a deficiência desempenha uma influência dobrada no desenvolvimento do sujeito:

Por um lado, é uma deficiência e atua diretamente como tal, produzindo falhas, obstáculos, dificuldades na adaptação da criança. Por outro lado, exatamente porque o defeito produz obstáculos e dificuldades no desenvolvimento e rompe o equilíbrio normal, ele serve de estímulo ao desenvolvimento de caminhos alternativos de adaptação, indiretos, os quais substituem ou superpõem funções que buscam compensar a deficiência e conduzir todo o sistema de equilíbrio rompido a uma nova ordem. (VIGOTSKI, 2011, p. 869).

Sendo assim, este olhar indica que não se considere apenas as falhas e faltas do sujeito, mas também um contexto vívido de suas funções psicológicas superiores que via trazer em seu bojo uma demanda de caminhos indiretos. O desenvolvimento destas funções somente será possível pelos chamados caminhos culturais de desenvolvimento, portanto:

Seja ele pela linha do domínio dos meios externos da cultura (fala, escrita, aritmética), ou pela linha do aperfeiçoamento interno das próprias funções psíquicas (elaboração da atenção voluntária, da memória lógica, do pensamento abstrato, da formação de conceitos, do livre-arbítrio e assim por diante). As pesquisas mostram que a criança anormal, em geral, tem atrasos justamente nesse aspecto. Tal desenvolvimento não depende da deficiência orgânica. (VIGOTSKI, 2011, p. 869).

Ainda em seus estudos, apresenta os chamados caminhos alternativos, que serão importantes para o desenvolvimento cultural e não se relaciona com a determinada função biológica na qual o sujeito tem alguma deficiência. Portanto, é através da criação destes caminhos indiretos de desenvolvimento quando não é possível o desenvolvimento pelo caminho habitual - que o desenvolvimento e aquisição de conceitos se estabelecerão.

Vigotski (2001; 2012) define e categoriza deficiência em duas: a deficiência primária, parte física do indivíduo (lesões orgânicas, cerebrais, malformações, alterações cromossômicas entre outras) e deficiência secundária, aquela que é social, deficiência na interação com a sociedade, pois, parte do pressuposto que o meio social esta organizado para as pessoas sem deficiência, o que causaria dificuldades de acesso às pessoas com deficiência.

Como ressalta:

Todo o aparato da cultura humana (da forma exterior de comportamento) está adaptado à organização psicofisiológica normal da pessoa. Toda a nossa cultura é calculada para a pessoa dotada de certos órgãos mão, olho, ouvido - e de certas funções cerebrais. [...] Todos os nossos instrumentos, toda a técnica, todos os signos e símbolos são calculados para um tipo normal de pessoa. (VIGOTSKI, 2011, p. 867).

Em sua teoria, Vigotski (2012) discute a compensação biológica que, miticamente, se tem noção de que os sujeitos com deficiência possuem, como por exemplo, pessoas surdas possuem uma visão superior ou pessoas cegas uma audição extraordinária. Para ele, não há uma compensação biológica, e sim, social, pois o sujeito poderá superar suas limitações como base em instrumentos que podem ser estratégias, meios e signos para compensar efetivamente a deficiência. A educação surge em auxílio das pessoas com deficiência através da criação de técnicas artificiais, culturais, um sistema especial de signos ou símbolos culturais adaptados às peculiaridades da organização psicofisiológica da criança com deficiência. 
Os cegos e os surdos-mudos são como um experimento natural que demonstra que o desenvolvimento cultural do comportamento não se relaciona, necessariamente, com essa ou aquela função orgânica. A fala não está obrigatoriamente ligada ao aparelho fonador; ela pode ser realizada em outro sistema de signos, assim como a escrita pode ser transferida do caminho visual para o tátil... Nós nos acostumamos com a ideia de que o homem lê com os olhos e fala com a boca, e somente o grande experimento cultural que mostrou ser possível ler com os dedos e falar com as mãos revela-nos toda a convencionalidade e a mobilidade das formas culturais de comportamento. Psicologicamente, essas formas de educação conseguem superar o mais importante, ou seja, a educação consegue incutir na criança surda-muda e na cega a fala e a escrita no sentido próprio dessas palavras. (VIGOTSKI, 2011, p. 868).

Vigotski (2011) exemplifica, que, por exemplo, para a criança com deficiência intelectual, deve ser criado, relacionando ao seu desenvolvimento das funções superiores de atenção e pensamento, um sistema ou meio semelhante ao código braille para os cegos ou a datilologia para os surdos. O que constatamos, é a proposição de um sistema de caminhos indiretos para o desenvolvimento cultural e escolar, já que a deficiência pode trazer alguns impedimos para a sua aquisição direta. Sendo estes caminhos indiretos formas peculiares de ensinar devem ser prensadas e respeitadas, observando-se às necessidades educacionais de pessoa com deficiência.

\section{Educação de Surdos: historicidade, contexto e novos olhares}

A educação de pessoas surdas, no Brasil, teve origem com a Fundação do Imperial Instituto de Surdos-Mudos, em 1857, e a chegada do educador francês
Hernest Huet, surdo congênito, no período do segundo império. Ex-diretor do Instituto de Surdos de Paris, Huet foi trazido com a incumbência de ajudar através de sua ampla experiência conseguida durante a sua tarefa com alunos surdos, nos primórdios da caminhada do Brasil com as ações relacionadas à educação de pessoas surdas. D. Pedro II teve a ideia de trazê-lo para trabalhar nessa área através de um benefício patrocinado pelo próprio governo brasileiro, a priori, na instrução de duas garotas surdas. Huet trouxe uma metodologia de ensino que trabalhava com o uso de sinais, baseado na sua atuação anterior na França, usando a Língua Francesa de Sinais - uma das influências da Língua Brasileira de Sinais (Libras) conforme estudos comparativos e também o documento e intitulado Iconographia dos Signaes dos Surdos-Mudos. (GAMA, 1975).

Acompanhando uma predisposição mundial, devido aos resultados do Congresso de Milão, em 1880, em que se ficou decidido que o uso da língua oral era o mais indicado na educação de pessoas surdas. Em 1911, o Imperial Instituto de Surdos-Mudos, que mais tarde se chamaria de Instituto Nacional de Educação de Surdos (INES) instituiu em seu currículo o Oralismo (ensino para pessoas surdas com base na comunicação oral, através de treinamentos de leitura orofacial e de fala, baseado em diferentes metodologias, geralmente utilizando resíduos auditivos) como método de ensino.

Embora houvesse muitas proibições, a língua de sinais sempre foi empregada pelos alunos surdos nos ambientes escolares, exceto a sala de aula. Tal resistência à utilização dos sinais persistiu até 1957, ano em que a diretora do Instituto, Ana Rimola de Faria Doria, aconselhada pela professora Alpia Couto, proibiu oficialmente a prática de sinais em sala de aula. Desde então, todos os alunos que utilizassem a língua de sinais, no ambiente 
da sala de aula, seriam penalizados. Mesmo assim, fora do instituto os alunos seguiam fazendo uso dos sinais para se comunicarem, principalmente, nas sociedades que se ganhavam forma em meio aos grandes centros urbanos do Brasil. (SOFIATO; REILY, 2011).

Contudo, a história da educação de surdos, no Brasil, não está restrita unicamente a fundação do Instituto pelo educador francês Hernest Huet, no Rio de Janeiro. Muitos outros projetos foram empregados em diversos estados do país. Como, quando em São Paulo, apenas por volta de 1930, a iniciativa religiosa marcou o início do apoio educacional da pessoa surda; sendo a única predominante pelos próximos 20 anos. Somente em 1950 é que começam a surgir as iniciativas públicas e de pais de surdos; como o Instituto Hellen Keller e o Instituto Educacional de São Paulo. Em 1957, a rede estadual de ensino criou a classe especial de apoio aos alunos surdos, e todas estas instituições faziam uso do método oral. (BALIEIRO, 1989)

Todas as escolas especiais do Brasil, voltadas à educação de pessoas surdas tinham como método de ensino, o oralismo. O objetivo dessas escolas era expandir um trabalho no primeiro período do ensino fundamental e, em seguida, dirigir esses alunos as instituições de ensino regulares com o intuito de integralizá-los aos alunos ouvintes.

Segundo Perlin (2002, p. 14):

A educação de surdos ocorreu em ambientes especiais, separados de crianças ouvintes, pelo menos para o ensino básico. Apenas eram encaminhadas para a escola comum aquelas crianças que se mostrassem aptas a acompanhar a rede regular de ensino, isto é, que tivessem adquirido uma fala boa e inteligível tivesse também uma boa leitura labial, além de já estarem alfabetizadas [...] A esses surdos não era permitido usar qualquer gesto além dos naturais, com a justificativa de que esses acabavam por inibir a iniciativa, ou o desejo, da criança pela fala.

Durante essa época, a educação de pessoas surdas era feita para eles, mas idealizada por e para pessoas ouvintes, ou seja, as pessoas surdas tinham que ficar contentes pelo simples fato de receberem educação, mesmo essa educação se dando a cargo de pessoas ouvintes e sem atender às suas necessidades educacionais especiais. Ao longo da história da educação de surdos é fácil perceber que a falta de audição era o motivo principal para o tamanho sofrimento dos mesmos, uma vez que eram privados de participar da vida social como as pessoas ouvintes. Sendo assim, o motivo de a educação de surdos ser fundamentada no Oralismo ou na indelicada tentativa de fazer o surdo falar, no Brasil e em outros países do mundo, era puramente para que os mesmos tivessem a oportunidade de viver e ser como as pessoas ouvintes.

A partir do século XIX até 1960, o sistema de educação oral prevaleceu na educação de surdos, no Brasil. A língua de sinais foi gradativamente sendo inutilizada nos ambientes das salas de aula, já que os educadores acreditavam que as pessoas surdas tinham como obrigação primeiramente aprender a "falar" tanto para serem alfabetizados como também para serem inteirados aos ouvintes.

O método da Comunicação Total chegou, no Brasil, por volta dos anos 1970, após a visita da educadora de surdos da Universidade de Gallaudet, Ivete Vasconcelos. De acordo com Ciccone (1996), a Comunicação Total é uma completa liberdade de quaisquer estratégias educacionais, que permitirão o docente usar para ensinar o surdo, já que comunicação oral pode estar, total ou parcialmente bloqueada. Através desse novo método de ensino o aluno surdo tem a permissão de escolher quais seriam os recursos que eles se valeriam para executar a comunicação: língua de sinais, gesto, mímica, leitura-escrita, fala e leitura labial. 
A ampla indagação relacionada à Comunicação Total é a seguinte: como poderia uma criança surda escolher a língua de sinais, fala, leitura labial e leitura escrita uma vez que a mesma começa na escola desprotegido dessas habilidades? Mesmo que a criança conheça alguns gestos, na maioria das vezes, inventados para que aja o diálogo entre a mãe e a criança, os mesmos serão empregados exclusivamente dentro desse contexto, e serão identificados como sinais caseiros. Marchesi (1987) afirma que não é relevante apresentar diferentes formas de comunicação para as pessoas surdas, e sim se certificar se tais formas, códigos de comunicação estão sendo aplicados de forma eficiente, que era o principio básico da Comunicação Total: a efetividade na comunicação, independentemente de qual meio ou estratégia.

O método da Comunicação Total na educação de pessoas surdas foi alvo de inúmeras críticas no país. Nos anos 1980, surgiram as primeiras discussões a respeito do Bilinguismo, provenientes das pesquisas realizadas sobre a Libras, pela professora e linguista Lucinda Ferreira Brito.

A aquisição da Língua de Sinais por pessoas surdas se dará a partir do momento em que houver interação com outros usuários da Língua de Sinais. A partir do segundo ano de vida de uma criança surda, havendo tal interação, as mesmas têm condições de produzir restritas configurações de mãos (conjunto de unidades fonológicas mínimas da língua de sinais, semelhante às unidades sonoras das línguas faladas), assim como simples composições de sinais que manifestem fatos pautados no interesse efetivo, como, por exemplo, o aqui e o agora. Fernandes (2005, p. 92), afirma que:

[...] para que as crianças surdas possam compartilhar as práticas culturais do contexto social dos ouvintes cujos símbolos que impregnam a cultura só vão se revestir de significado para as crianças surdas se houver interações sociais e comunicativas significativas que possam decodificar símbolos.

Por ser o primeiro ambiente que possibilita o contato das crianças surdas com a LIBRAS, a escola tem o papel de se tornar o espaço linguístico imprescindível para elas. É através da língua de sinais que a criança surda terá a oportunidade de adquirir a linguagem, ou seja, através dela a criança estará criando uma nova esfera fazendo uso de uma linguagem compreendida e válida durante o seu uso. De acordo com Karnopp (2002), as pessoas não constroem significados em vácuo, logo, tal sistema propicia a interpretação através da escrita que pode ser na LIBRAS, assim também, como na Língua Portuguesa.

A hipótese que dirige tal padrão de ensino é que a pessoa surda tem por obrigação ser bilíngue, ou seja, ela deve assumir a Língua de Sinais, considerada a língua natural dos surdos, como Língua Materna (L1) e como Segunda Língua (L2), a língua de ordem (oficial) de seu país dentro da característica oral e da escrita. Sanches (1993) crer que se faz necessário para a pessoa surda adquirir tanto a língua de sinais como também a língua oficial do seu país de origem unicamente na modalidade escrita e também não oral.

Para Skliar (1999), a educação bilíngue exige do professor uma postura política, pois ensinar aos surdos e não surdos, exige o reconhecimento dos direitos humanos concernentes aos sujeitos, e mais do que isto, exige do professor compreensão dos aspectos ideológicos oriundos das práticas focadas a oralização e sobre a natureza epistemológica sobre as representações sociais sobre surdos e surdos.

Uma das teorias mais relevantes desse método de ensino é que as pessoas surdas formam um grupo social com língua e cultura peculiares. Para os bilinguistas, as pessoas 
surdas não necessitam desejar uma vida idêntica a das pessoas ouvintes, uma vez que os surdos podem admitir e assumir a surdez.

Muitas causas comprometem a adesão ao bilinguismo, falta uma estrutura sugerida para a sua aplicação. As aulas de língua portuguesa, em escolas públicas, são ministradas por professores ouvintes que, em sua maioria, não possuem o domínio da língua de sinais. Outra dificuldade que inviabiliza a promoção do conhecimento, na sala de aula, é percebida através do número insuficiente de intérpretes presentes no ambiente da sala de aula, embora se saiba que, mesmo tendo a presença desse profissional, não se tem a total garantia de compreensão do conhecimento transmitido. Vale ainda dizer que, o intérprete não pode ser o único profissional a se comunicar com o aluno surdo. Este profissional é o responsável por mediar a construção do conhecimento oferecida pelo professor ao aluno.

De acordo com o bilinguismo, o domínio da língua de sinais se torna mais fácil para que os alunos surdos compreendam tais aspectos também na língua oral, uma vez que podem utilizar como norte os exemplos da língua de sinais.

Segundo Goldfeld (1998), o bilinguismo, adotado nas últimas décadas, tem contribuído para o melhor desempenho escolar dos surdos. Assim como muitos outros países que compõe o continente sul-americano, o Brasil é considerado um país monolíngue, ou seja, de uma única língua. Entretanto, compreende-se que há várias comunidades que falam muitas línguas dando assim a característica de bilíngue ao Brasil, mesmo não confirmado como este. Confia-se que, no Brasil, todo falante adquire a Língua Portuguesa como língua materna (L1), desconhecendo o fato de se ter vários outros falantes vindos de grupos imigrantes, como por exemplo, japoneses, italianos, entre outros, e ainda as diversas línguas das comunidades indígenas, a partir daí, entende-se que o Brasil é uma nação multilíngue.

Determinar o bilinguismo depende de diversos questionamentos de cunho político, social e cultural, uma vez que, as políticas linguísticas brasileiras tendem por excluir as línguas, quando na realidade deveria utilizar uma política linguística que permitisse a soma dessas diversas línguas para a edificação da cultura substancial do país. Por ser a Língua Portuguesa a língua oficial do país, não há o incentivo de uma língua de sinais de boa qualidade, como também a pluralidade de línguas brasileiras não é incluída no espaço escolar, considerando também o artefato cultura que a Libras apresenta.

Graças a essas questões políticas, sociais, entre outras, é que ainda não existe um acordo no que se refere à concepção e classificação do bilinguismo. De acordo com Fernandes (2005, p. 28), “[...] o Bilinguismo, entre tantas possíveis definições, pode ser considerado: o uso que as pessoas fazem de diferentes línguas (duas ou mais) em diferentes contextos sociais.”

Entendendo que o atraso do ensino da LIBRAS nas escolas brasileiras agrega mais complexidades à questão essencial da perda auditiva. Para Fernandes (2005) a grande maioria das pessoas surdas cresce em famílias de pais que ouvem a Língua Portuguesa, mas não a adquirem prematuramente. Sendo assim, frequentando espaços educacionais em que o ensino é executado em Língua Portuguesa, com um pequeno número de professores dominantes da Libras, os alunos surdos tendem a desenvolver mais dificuldades na aquisição da mesma. Logo, o compartilhamento dessas duas línguas a partir da infância, não significa atender as principais orientações desse padrão, uma vez que a participação do intérprete da língua não represente certeza de aprendizado da língua de sinais. 
Estudos realizados por diversos teóricos, como Quadros (1997, 2006, 2007, 2008, 2009); Karnopp (2006); Fernandes (2005), Ferreira Brito, (1993), alegam que as pessoas surdas possuem a capacidade de aprender a ler e escrever em português sem necessariamente aprender a pronunciar tal idioma, da mesma maneira que se aprende uma língua estrangeira escrita sem saber articular suas palavras.

A filosofia bilíngue da educação de surdos recomenda que essa criança adquira a Língua de Sinais como primeira língua, satisfazendo as necessidades comunicativas, emocionais, cognitiva e linguística do indivíduo, e como segunda, a língua de modalidade oral-auditiva de sua comunidade, no caso do Brasil, o português. (GOLDFELD, 2000). Assim também pensa Almeida (2000) que a língua de sinais deve ser aprendida logo após o diagnóstico da surdez, deve ser o mais precoce possível e a posteriori em caráter da modalidade escrita.

Sendo assim, nas perspectivas da Educação de Surdos, o Bilinguismo torna-se aquele que melhor entende o desenvolvimento linguístico e cognitivo dos surdos, e é, portanto, considerado a forma ideal de instrução e comunicação. O histórico da Educação de Surdos apresenta todo o caminho trilhado pelos surdos, no mundo, a fim de entender o contexto atual. Além disso, é importante ressaltar que cada filosofia educacional possui uma visão diferente de sujeito e de linguagem e apresentam suas contribuições inegáveis as discussões da Educação de Surdos.

\section{A teoria vigotskiana e a educação de surdos}

Em relação à Educação de Surdos, é notável que Vigotski assume mudanças no seu entender e realiza modificações de sua teoria. Em 1925, seu primeiro texto sobre a educação de surdos, chamado "Princípios da Educação Social para Crianças Surdas” traz como principal estratégia e é favorável a oralização, assegurando que este tipo de estímulo será benéfico ao surdo, pois terá contato com a língua da maioria ouvinte, o mais cedo possível, nos primeiro anos da escola. Esta posição de Vigotski coincide com o auge da filosofia oralista, entrelaçando ideias entre os dois pensamentos.

Mais adiante, em 1931, em se texto intitulado "A coletividade como fator de desenvolvimento da criança anormal”, Vigotski cita a "mímica” (se referindo às línguas de sinais, pois ainda a mesma não havia adquirido seus status linguísticos naquela época) junto a diferentes formas de linguagem, apresentando uma utilização de vários recursos linguísticos para que o surdo tenha acesso à linguagem de qualquer forma, o que corrobora com os fundamentos da Comunicação Total, apesar do autor enfatizar o gestual, ainda mostra uma preocupação com as demais formas de linguagem que o surdo poderia utilizar para a sua comunicação com outros surdos e ouvintes.

Por não ouvir, o surdo dificilmente irá apoiar-se na relação oralidade/escrita o que tornará ainda mais relevante o aspecto visual no processo de aquisição/aprendizagem da língua escrita e demais conceitos. Como afirma Vigotski (2004), o desenvolvimento da linguagem escrita independe do desenvolvimento da fala e as funções mentais que envolvem são diferentes.

Para Vigotski (2007), a escrita é um processo que não será construído nos primeiros anos de escolaridade, e, sim ao longo da vida. O que nos leva a repensar nas concepções tradicionalistas do ensino de Língua Portuguesa escrita para surdos enfatizando o aspecto visual como fator constitutivo desse processo e (pseudo) fundamentadas no bilinguismo. 
Em relação às escolas de surdos, o ensino da leitura e escrita, por exemplo, funciona como um papel primitivo, avaliador, e no qual se impõe a superioridade do ouvinte - que domina a escrita - sobre o surdo - que não domina. Ou seja, trata-se de uma educação pensada por professores e gestores ouvintes para alunos surdos e, somado a isso, as formas de aprender com base na cultura oral, na perspectiva e análise do professor ouvinte e que tem como questionamento o fato de professor e aluno não compartilharem a mesma língua. Com base nisso, Giordani (2004, p. 77), propõe que:

Os professores de alunos surdos devam ser, preferencialmente, professores surdos com um perfil bilíngue bicultural, com habilidade dos distintos recursos linguísticos que derivam do domínio competente da língua de sinais. Quando o professor for ouvinte é importante uma imersão na comunidade surda, objetivando, além de uma competência em língua de sinais, uma compreensão da gramática, a partir das bases culturais.

Para Vigotski (2011) a educação ensina o surdo a perceber a língua falada pela leitura dos lábios do falante, ou seja, substituindo os sons da fala por imagens visuais, movimentos da boca e dos lábios. O surdo aprende a língua oral através de métodos que utilizam o tato, a imitação de sinais e as sensações de vibrações e movimentos.

A língua de sinais fará a mediação entre os interlocutores e embasa o processo de construção do conhecimento. Não se trata apenas de um instrumento ou código de tradução e suporte para o trabalho do professor, mas, sim, um traço de identidade de uma cultura. Por isso, é relevante a aceitação e compreensão dessa língua e o direito do aluno surdo a ter uma escolarização em que se concretizem suas possibilidades linguístico-cognitivas. O uso da língua de sinais oferece ao surdo um lugar social próprio.
A grande quantidade de insucessos na educação de surdos se dá, pois, se pensou que a solução de todos os 'problemas' relacionados à escolarização dos alunos surdos se daria somente com o uso da língua de sinais, esquecendo-se de repensar as metodologias utilizadas, como destaca coerentemente Campos, Kober e Melendez (2004, p. 51): "Ignorou-se que as metodologias, até então implementadas, carregam visões de mundo que determinam ações pedagógicas pensadas para crianças ouvintes, fazendo com que não houvesse reformulação no olhar e no fazer educacional no caso das crianças surdas”.

Os professores e profissionais envolvidos no contexto escolar devem abandonar o ideal de pureza que dão à escrita e tentarem repensá-la como uma forma de expressão caracterizada pela diversidade histórico-linguístico-social daquele que escreve. Ao professor, cabe se distanciar cada vez mais e de forma mais efetiva de alguns 'tradicionalismos' no ensino do Português, 'tradicionalismos' esses que se tornam ainda mais prejudicial quando usados na educação de surdos. Além disso, o professor assumirá o papel de mediador na aprendizagem do aluno surdo, será o adulto experiente - seja surdo ou ouvinte - que proporcionará a vivencia do aluno surdo na Zona de Desenvolvimento Proximal e, consequentemente, na sua aquisição de conhecimentos linguísticos e não-linguísticos.

Em relação à linguagem das crianças surdas, Vigostski (2011, p. 868), comenta:

E, para a criança surda-muda, o mais importante, do ponto de vista do desenvolvimento cultural, é que a fala humana é garantida por um aparato psicofisiológico completamente diferente [...] As crianças surdas-mudas, por si mesmas, desenvolvem uma língua mímica complexa, uma fala singular. É criada uma forma particular de fala não para surdos-mudos, mas construída pelos próprios surdos-mudos. 
É criada uma língua original, que se distingue de todas as línguas humanas contemporâneas mais profundamente do que estas entre si, pois ela retorna a mais antiga protolíngua humana, à língua dos gestos ou até mesmo só das mãos.

No capítulo denominado "Princípios da Educação Social para Crianças Surdas” Vigotski (2012) faz uma crítica severa à escola especial, ao separar a criança surda do convívio com as demais crianças. Mesmo em meados de 1925, o autor já trazia em suas perspectivas que a melhor forma de educar essas crianças seria uma Pedagogia Social de Surdos. Além disso, o fato de Vigotski criticar as classes e escolas especiais corrobora com a filosofia bilíngue e a inclusão vivida pelos surdos, no Brasil, após a promulgação da Lei Federal brasileira 10.436/2002 e o Decreto $5.626 / 2005$. Estes documentos legais estabelecem escolas bilíngues ou escolas da rede regular de ensino, para alunos surdos e ouvintes, em qualquer etapa da vida escolar, com docentes das diferentes áreas do conhecimento, que compreendam a singularidade linguística dos alunos surdos e o ambiente de sala de aula linguisticamente complexo, bem como com a presença de tradutores e intérpretes de Libras e Língua Portuguesa.

Outra crítica de Vigotski está relacionada ao Oralismo e seu modelo severo de imposições ao utilizar métodos artificias além de frequentemente crueldade, pois era comum oralistas amarrarem as mãos dos alunos surdos para que o natural impulso de utilizar as mãos não aparecesse por ser algo tão natural ao surdo, diferentemente da linguagem oral.

Vigotski (2012, p. 341) insiste em apresentar os problemas da metodologia oralista:

O aluno não aprende a linguagem, mas somente a pronúncia das palavras; o desenvolvimento linguístico é inferior ao desenvolvimento geral; leva a criança a criar a própria linguagem - a mímica; a língua oral nada acrescenta aos surdos como instrumento de acumulação da experiência cultural e participação na vida social; inconsistente psicológica e pedagogicamente quando tenta formar palavras a partir dos sons e frases a partir das palavras.

A presença do instrutor surdo dentro da comunidade escolar, como condição para a prática do bilinguismo, terá como consequência a mediação pela língua de sinais e, portanto, a criança surda terá acesso ao mundo através dos signos pertencentes a sua língua natural. Sendo assim, a criança poderá entender o ambiente em que está inserida, direcionado pelo outro (o instrutor de Libras) e construir de forma gradativa uma ideia de si mesma e de contexto, esse outro que conferirá significado ao gesto da criança e aos objetos que estão ao seu redor. No momento em que a criança consegue realizar uma atividade, com ajuda do outro, pode-se entender então que o resultado dessa resolução, quando realizada sem ajuda, será distinto do produto da ação quando mediado pelo adulto, o que nos dá a ideia de Zona de Desenvolvimento Proximal.

Sendo assim, ao interagir com o instrutor de Libras, adulto e falante da Libras mais experiente, a criança surda tem a possibilidade de rever suas concepções e internalizar o que julgar mais adequado ou o que lhe fizer mais sentido, facilitando a compreensão do signo e do mundo.

Vigotski (2012) classifica a surdez como uma deficiência orgânica, considerada apenas do ponto de vista do desenvolvimento físico e formação da criança, não é vista como uma lacuna particularmente grave. $\mathrm{Na}$ maioria das vezes esta deficiência permanece mais ou menos isolada, sua influência direta sobre o desenvolvimento como um 
todo é relativamente pequena; geralmente não cria perturbações ou atrasos particularmente graves no desenvolvimento global. Além disso, enfoca que foi criada a língua de sinais, ou seja, o alfabeto digital e o discurso dos surdos.

Em nosso entendimento, a teoria de Vigostki contribui significativamente à Educação de Surdos assim como para a educação de todas as pessoas, se o professor buscar compreensão como o desenvolvimento semiótico e estruturante do pensamento humano ocorre, podendo pensar em práticas pedagógicas condizentes à realidade de seus educandos.

\section{Considerções finais}

Lev Vigotski teve sua maior contribuição na Psicologia da Educação, traçando os caminhos para a aprendizagem e o desenvolvimento. Em sua obra é notável o aporte em relação aos temas que envolveriam as funções psicológicas superiores, mais verticalmente as questões inerentes à linguagem e ao pensamento. Dentre tantas contribuições, os Fundamentos da Defectologia serviram de base para discutirmos sobre a criança com deficiência e seu desenvolvimento.

Para Vigotski, uma criança cujo desenvolvimento é mais complicado por conta da deficiência não é simplesmente uma criança menos desenvolvida que os demais, mas com um desenvolvimento realizado de outra maneira, realizando uma crítica à forma de entender o desenvolvimento das crianças com deficiência somente de forma qualitativa.

Em sua teoria, toda deficiência cria estímulos para elaborar uma compensação a partir de elementos no contexto social, gerando um processo de criação e recriação da personalidade da criança com a reorganização de todas as funções adaptativas e abertura de novos caminhos para o desenvolvimento.

Outro aspecto importante na teoria Vigotskiana se relaciona ao fato de abordar a deficiência numa díade: primária e secundária. Entendendo que a deficiência propriamente dita trará dificuldades que derivarão dele mesmo, daí a deficiência secundária, um desvio social, com redução da posição social da criança, através das condições que o meio possibilita ou não.

No caso da Educação de Surdos, Vigotski alerta sobre os caminhos culturais e indiretos que os surdos precisam percorrer para que o desenvolvimento aconteça, além disso, faz uma crítica ao Oralismo e a metodologia severa utilizada, além de reconhecer a Língua de Sinais como forma de comunicação dos surdos.

A obra de Lev Vigotski contribuiu em vários aspectos para Educação no mundo todo. Ao realizar um paralelo de seus pressupostos com a especificidade de Educação de Surdos, fica claro que Vigotski foi um estudioso além de seu tempo e com ideias que corroboram as teorias atuais e continua a contribuir nas reflexões a cerca da mediação e interação para a aprendizagem.

\section{Referências}

ALMEIDA, E. O. C. Leitura e surdez: um estudo com adultos não oralizados. Rio de Janeiro: Revinter, 2000.

ALVES, A. M. O método materialista histórico dialético: alguns apontamentos sobre a subjetividade. Revista de Psicologia da UNESP, Assis, v. 9, n. 1, p. 1-13, jan./ jun. 2010.

BALIEIRO, C. R. O deficiente auditivo e a escola: relatos de algumas experiências. São Paulo: PUC, 1989. 
BRASIL. Decreto $\mathbf{n}^{\mathbf{0}}$ 5.626, de 22 de dezembro de 2005. Regulamenta a Lei no 10.436, de 24 de abril de 2002. Brasília: Senado Federal, 2005.

. Ministério da Educação. Secretaria de Educação Especial. Lei No $\mathbf{N}^{\mathbf{0}} \mathbf{1 0 . 4 3 6 .}$ Brasília: Senado Federal, 2002.

CAMPOS, S. R. L. de; KOBER, D. C.; MELENDEZ, A. J. O recurso midiático como portador de texto no letramento de crianças surdas. In.: LODI, A. C. B.; HARRISON, K. M. P.; CAMPOS, S. R. L. de. (Orgs.). Leitura e escrita no contexto da diversidade. Porto Alegre: Mediação, 2004. p. 50-59.

CICCONE, M. Comunicação total: introdução, estratégias a pessoa surda. Rio de Janeiro: Cultura Médica, 1996.

FERNANDES, E. (Org.) Surdez e bilinguismo. Porto Alegre: Mediação, 2005.

FERREIRA BRITO, L. Integração social \& educação de surdos. Rio de Janeiro: Babel, 1993.

GAMA, F. J. da. Iconographia dos signaes dos surdos-mudos. Rio de Janeiro: Tipografia Universal de E. \& H. Laemmert, 1975.

GIORDANI, L. F. Encontros e desencontros da língua escrita na educação de surdos. In.: LODI, A. C. B.; HARRISON, K. M. P.; CAMPOS, S. R. L. de. (Orgs.). Leitura e Escrita no contexto da diversidade. Porto Alegre: Mediação, 2004. p. 73-85.

GOLDFELD, M. A criança surda: linguagem e cognição numa perspectiva sociointeracionista. São Paulo: Plexus, 1998.

KARNOPP, L. B. Língua de Sinais e Língua Portuguesa: em busca de um diálogo. In.: LODI, A. C. B; HARRISON, K. M. P;
TESKE, O. (Orgs.). Letramento e minorias. Porto Alegre: Mediação, 2002. p. 56-61.

KARNOPP, L. B.; MACHADO, R. N. Literatura surda: ver histórias em língua de sinais. 2. Seminário Brasileiro de Estudos Culturais em Educação (CD) - 2SBECE. Canoas: ULBRA, 2006.

MARCHESI, A. El desarrollo cognitivo e linguístico de los ninõs sordos: perspectivas educativas. Madri: Alianza, 1987.

PERLIN, G. T.T. et al. História dos surdos. Florianópolis: UDESC/CEAD, 2002.

QUADROS, R. M. Estudos surdos IV. Petrópolis: Arara Azul, 2009.

Estudos surdos III. Petrópolis: Arara Azul, 2008.

Aquisição da língua de sinais brasileira: constituição e transcrição dos corpora. Brasília: UnB, 2007.

- Educação de surdos: a aquisição da linguagem. Porto Alegre: Artmed, 1997.

QUADROS, R. M.; SCHMIEDT, M. L. P. Ideias para ensinar Português para alunos surdos. Brasília: MEC: SEESP, 2006.

SANCHES, C. Vida para os surdos. Revista Nova Escola. Rio de Janeiro: Abril, 1993.

SKLIAR, C. A surdez: um olhar sobre as diferenças. Porto Alegre: Mediação, 1999.

SOFIATO, C. G.; REILY, L. H. “Companheiros de infortúnio": a educação de "surdos-mudos" e o repetidor Flaustino da Gama. Revista Brasileira de Educação, Rio de Janeiro, v. 16, n. 48, p. 625-640, set./ dez. 2011.

VIGOTSKI, L. S. Psicologia pedagógica. São Paulo: WMF, 2016. 
. Obras escogidas V: fundamentos de defectologia. Madrid: Machado Libros, 2012.

A defectologia e o estudo do desenvolvimento e da educação da criança anormal. Educação e Pesquisa, São Paulo, v. 37, n. 4, p. 861-870, jan./dez. 2011.

A construção do pensamento e da linguagem. São Paulo: WMF, 2010.

A formação social da mente. São Paulo: Martins Fontes, 2007.

Teoria e método em psicologia.

São Paulo: Martins Fontes, 2004. 